\title{
Compilation and Analysis of Systemic Risk Index of Sci-tech Innovation Board Market
}

\author{
Yongjie Zhang ${ }^{1}$ Chengyi $\mathrm{Pu}^{2, *}$ \\ ${ }^{1}$ Yongjie Zhang. Central University of Finance and Economics, School of Accountacy \\ Email:2019310561@email.cufe.edu.cn \\ 2 * Chengyi Pu. Corresponding author. Central University of Finance and Economics, School of Insurance \\ Email: pucy@cufe.edu.cn
}

\begin{abstract}
Since the establishment of the sci-tech innovation board, the government lacks effective means to supervise the market risk of the sci-tech innovation board, and it is difficult for investors to accurately grasp the risks in the market. But now, the research on the systematic risk of the sci-tech innovation board is a blank, and the existing research has not provided help for the government regulation and investors to quantitatively measure the risk degree of the sci-tech innovation board market. Based on the critical weighting method, this paper establishes the financial pressure index (FSI) of the sci-tech innovation board market by using six indicators, such as volume decline, stock index amplitude, stock index decline, liquidity decline, stock market turnover rate, and the average value of predicted predicted return on equity, to comprehensively measure the financial pressure faced by the science and technology innovation board market.
\end{abstract}

Keywords: The Sci-Tech innovation board, Financial pressure index, Criteria Importance Though Intercriteria Correlation

\section{科创板市场系统性风险指数的编制分析}

\author{
张永婕 ${ }^{1}$ 蒲成毅 $2, *$
}

\author{
${ }^{1}$ 张永婕，中央财经大学 会计学院，电子邮箱: 2019310561@emai1.cufe.edu.cn \\ 2*蒲成毅 (通讯作者), 中央财经大学 保险学院, 电子邮箱: pucy@cufe.edu.cn
}

\section{摘要}

科创板创立以来政府缺乏监管科创板市场风险的有效手段，投资人难以准确把握科创板市场上的风险。目前 对科创板系统性风险的研究仍是空白。本文基于 CRITIC 赋权法，使用成交量跌幅、股指振幅、股指跌幅、流 动性跌幅、股市换手率、预测净资产收益率平均值等六个指标构建科创板市场金融压力指数（FSI），综合测 度科创板市场面临的金融压力，为政府监管和投资者定量地测度科创板市场的风险程度提供帮助。

关键字: 科创板，金融压力指数，CRITIC 赋权

\section{1. 引言}

2018 年 11 月科创板宣布设立。2019 年 7 月下 旬首批 25 家科创企业正式上市。2020 年 7 月科创 板 50 指数正式发布。科创板定位 “主要服务于符合 国家战略、突破关键核心技术、市场认可度高的科 技创新企业”，具有深刻的历史意义。科创板是新
规则、新机制的 “试验田”。首次试点注册制，首 次允许亏损企业上市，首次允许特殊股权结构的企 业上市，首次为科创企业提供包容性多通道的 IP0 标准，首次采用新股上市头 5 个交易日没有涨跌幅 的限制，完成了多个 “首次”。科创板初创即成果 斐然。然而, 科创板市场在蓬勃发展的进程中也累 积了系统性金融风险。在如今中美关系紧张，全球 新冠肺炎大流行、全球贸易量萎缩的形势下，我国 
遭受了巨大的经济损失, 也影响了我国金融系统各 层次的发展, 科创板也不能例外。

定量的测度科创板市场系统性金融风险对于维 护科创板市场的平稳发展有着重大的意义。基于金 融压力指数方法, 本文将选择适合科创板具体情况 的各项指标, 建造能反映市场风险状态的指标体 系，构建科创板市场的金融压力指数，从而为科创 板市场系统性金融风险的识别、检测和预防提供理 论基础和监督指导。

\section{2. 文献综述}

在运用金融压力指数测度金融风险的问题上, 国内外研究成果颇丰。Illing 和 Liu（2006） [1]首 先提出金融压力指数 (FSI) 的概念, 还构造了加拿 大日度金融压力指数。随后, 国外许多学者和研究 机构进一步完善了金融压力指数体系。IMF（2008） [2]改进金融压力指数体系, 选取 3 个银行部门变 量, 3 个证券市场变量和 1 个外汇市场变量, 利用 等方差权重法编制一个独立的金融压力指数。 Hakkio 和 Keeton（2009）[3]选取美国主要金融市场 中 11 个能充分反映金融压力特征的变量构建了堪萨 斯金融压力指数。Balakrishnan（2009）[4]构建了 新兴国家的金融压力指数, 并研究了金融压力在发 达国家与新兴国家之间的传播机制。Gadanecz 和 Jayaram（2010） ${ }^{[5]}$ 回归与总结了前人金融压力指 数, 指出历史压力事件被各种金融指数反映的效果 较为良好, 但还需进一步测试其对金融压力的预测 能力。Cardare11i (2011) [6]研究了 17 个国家的金 融市场风险，选取了 7 个指标编制了金融压力指 数。Louzis\&Vouldis（2012）[7]使用了资产负债表 和市场的相关数据建立了希腊的金融系统性压力指 数。Bianco（2012） ${ }^{[8]}$ 等分别从货币、外汇、信 贷、股权、房地产和债券等六大市场中选取了 16 个 金融指标来构建金融压力指数。Momin（2017）[9]以 全球金融市场日度交易数据测度金融市场压力构建 了 OFR FSI 指数。

国内对金融压力指数及相关问题的研究也很广 泛。靳玉英（2013） [10]运用金融压力指数和面板 VAR 模型研究主要金融领域风险的传染性及其对宏 观审慎监管的政策含义。余文君（2014）[11]构造上 海 $\mathrm{A}$ 股市场金融压力指标体系, 建立上海 $\mathrm{A}$ 股市场金 融压力指数, 并通过金融压力指数实证分析了上海 A 股市场的系统性金融风险。李敏波（2013）[12]运 用 IMF 及部分央行的理论方法, 利用 GARCH 模型估 计我国股票市场的波动性, 辅之以股票市场涨跌情 况, 构建我国股票市场的市场压力指数。郑桂环 （2014） [13]选用 10 个反映金融压力状况的指标, 采 用指标标准化方法、 CDF 处理方法、主成分分析方 法、动态因子模型方法构建了不同的金融压力指 数。许涤龙（2015） [14]基于 CRITIC 赋权法构建金融 压力指数 (FSI), 并从银行、房地产、股票市场和 外部金融市场综合测度我国面临的金融压力。章曦
（2015）[15]先构建了我国系统性金融风险的金融压 力指数和分指数, 其次建立了识别指数, 最后利用 ARMA 模型对风险趋势进行了拟合和预测。许悦 （2017） [16]构建了 CISS，综合了四个子市场的 12 个金融指标，借鉴标准组合理论的思路，基于指标 间交叉相关性计算，用于反映美国系统性风险状 况。仲文娜（2018） [17]构建了月度的中国金融体系 压力指数 (CFSSI) , 并利用金融压力事件识别法和 马尔科夫转移自回归 (MS-AR) 模型, 对该指数识别 效果进行检验。

国内对科创板市场风险的研究主要集中在对科 创板上市企业的风险的研究, 缺少对科创板整个板 块的风险定量的研究。张同功 (2020) [18]构建了 WBS-RBS 风险识别矩阵, 运用问卷调查法, 对科创 板企业的运营风险进行了识别。陶秋月（2020）[19] 基于 KMV 模型和有序 Logit 模型, 对我国科创板上 市公司信用风险进行了评估。申万宏源课题组 （2020）[20]深入剖析了科创板运行中与市场定价、 构建良性信息披露生态、交易制度相关风险点, 并 提出了科创板试点注册制的风险防范建议。

综上，现有成果主要探讨的是金融压力的概 念、金融压力指数的变量选取和构造等问题。在科 创板市场面临风险, 国内主要围绕科创板试点注册 制和审计方面的风险进行研究, 缺乏对科创板整个 板块系统性风险的研究。

因此，本文拟构建基于 CRITIC 权重的金融压力 指数（FSI）表征我国科创板市场的金融压力水平。 FSI 可为科创板市场系统性金融风险的测度提供依 据，并对金融风险加以判断。当 FSI 较大时，表明 系统性金融风险压力水平较高; 反之则较低。

\section{3. 理论分析}

金融压力指数是反映整个金融体系由于不确定 性和预期变化所承受的总体压力水平的综合性指 标。为了科学地测度科创板市场的系统性风险, 系 统性风险指数的变量选取要遵从科学、合理和实用 原则。因此，本文选择六个科创板市场的指标。假 定这六个指标组成的指标体系能反映市场风险状 态, 指标体系不同组合的结果状态就是风险的等 级。表一给出了具体指标的定义和其计算方法。数 据频率选定为每天，数据样本区间选定为 2020 年 1 月 3 日至 2020 年 8 月 31 日。数据来源均为WIND数据库。

科创板的流动性采用以下方法衡量:

$$
\text { Liquidty }=\frac{\text { turnover }}{\left(P_{t}^{\text {high }}-P_{t}^{\text {low }}\right) / P_{t}^{\text {low }}}
$$

其中，turnover 表示股票 $i$ 在第 $t$ 日的换手率， $P_{i, t}^{h i g h}$ 表示股票 $i$ 在第 $t$ 日的最高价格, $P_{i, t}^{l o w}$ 表示股票 $i$ 在第 $t$ 日的最低价格。为了防止上述计算公式中的分 母为零, 所以当 $P_{i, t}^{h i g h}=P_{i, t}^{\text {low }}$, 本文采用 0.001 来替 代。 
将选取的指标分为正向指标和负向指标。正向 指标越大表示金融压力越小，负向指标则相反。

金融压力指数的计算公式为

$F S I_{t}=\sum_{t=1}^{n} \omega_{i} X_{i t}$

其中, $\omega_{i}$ 为第 $i$ 个变量的权重, $X_{i t}$ 为第 $i$ 个变量 在第 $t$ 天的值。

权重确定方法采用CRITIC法，第 $j$ 个指标客观权 重 $W_{j}$ 计算公式为:

$W_{j}=\frac{C_{j}}{\sum_{j=1}^{n} C_{j}}, j=1,2,3, \ldots, n$

其中, $C_{j}=\sigma_{j} \sum_{i=1}^{n}\left(1-r_{i j}\right), j=1,2,3, \ldots, n$

表示第 $j$ 个评价指标所包含的信息量大小; $\sigma_{j}$ 为 标准差。

\section{4. 实证分析}

\section{1. 指标的预处理}

指标的标准化采用极差法。设 $X_{i}$ 为第 $\mathrm{i}$ 个指标标 准化后的值, $x_{i}$ 为第 $\mathrm{i}$ 个评价对象的值，则正向指标 标准化方法如式(4)所示:

$X_{i}=\frac{x_{i}-\min \left(x_{i}\right)}{\max \left(x_{i}\right)-\min \left(x_{i}\right)}$

负向指标标准化方法如式(5)所示:

$X_{i}=\frac{\max \left(x_{i}\right)-x_{i}}{\max \left(x_{i}\right)-\min \left(x_{i}\right)}$

\section{2. 系统性金融风险测度与分析}

将选取的日度数据经过预处理后, 以式(3)确定 的各个子系统权重, 得到科创板系统性风险指数的 测算公式:

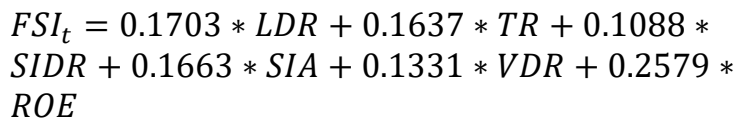

由式(6)可知，各个指标的权重比较接近，表明 各个指标对科创板市场的影响没有显著性差异。预 测净资产收益率平均值的权重最大，股指跌幅的权 重最小。这说明预测净资产收益率的变动对整个科 创板市场影响最大。

根据式(6)可测度出科创板市场在2020年1月3日 至2020年8月 31 日期间共 160 个交易日内具体的系统 性风险指数数值，其发展趋势可更加直观地体现在 折线图中（如图1所示）。

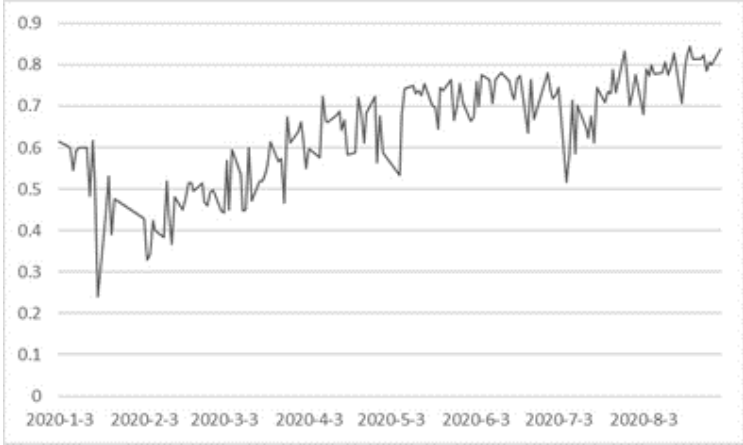

图1 2020年1月3日至8月31日科创板FSI

从图1可以看出, 科创板市场系统性风险指数图 形属于M型曲线。FSI图像分成明显的波段, 虽然在 每一个波段中波动幅度大，可是长期来看表现出上 升的趋势。可以预测，现在仍处于科创板市场系统 性风险积聚的时期, 风险还没有释放。

其中，在1月17日和5月6日这两天，科创板市场 的系统性风险指数都急剧下跌。在 1 月 17 日, 科创板 市值一举突破万亿大关, 与此同时, 芯片产业龙头 企业中微公司当天市值达到 1048. 38亿元, 科创板出 现首个突破市值千亿大关的企业。科创板股票全线 爆发, 午后持续走高。各机构对科创板的预期变 好, 这导致FSI中的正向指标预测净资产收益率平均 值升高。5月6日当天召开了国务院常务会议，会议 要求, 要把做好 “六保” 作为 “六稳” 工作着力 点, 稳住经济基本盘。进一步落实落细已出台的支 持企业纾困发展政策，让企业得到更多实惠，稳定 就业岗位，保障基本民生。国务院发布关于同意在

表 1 科创板 FSI 指标体系

\begin{tabular}{|c|c|c|c|}
\hline 指标名称 & 定义及说明 & $\begin{array}{l}\text { 变量 } \\
\text { 性质 }\end{array}$ & $\begin{array}{l}\text { 单 } \\
\text { 位 }\end{array}$ \\
\hline $\begin{array}{c}\text { 预测净资产收益率 } \\
\text { 平均值ROE }\end{array}$ & $\begin{array}{l}\text { WIND科创板 } 50 \text { 指数截至指定交易日, 各机构对该证券未来某年净资产收益率预 } \\
\text { 测值的算术平均。 }\end{array}$ & 正向 & $\%$ \\
\hline 股指振幅SIA & WIND科创板 50 指数指定交易日最高价与最低价之差与前收盘价的比率 & 负向 & $\%$ \\
\hline 成交量跌幅VDR & WIND科创板 50 指数在指定交易日收盘价与钱收盘价之差和前收盘价的比率 & 负向 & $\%$ \\
\hline 流动性跌幅LDR & WIND科创板 50 指数在指定交易日流动性与前流动性之差与昨日流动性的比率 & 负向 & $\%$ \\
\hline 股市换手率TR & 科创板总成交额和总市值之比 & 负向 & $\%$ \\
\hline 股指跌幅SIDR & $\begin{array}{l}\text { WIND科创板 } 50 \text { 指数在指定交易日的收盘价相对前收盘价的涨跌百分比, 正值为 } \\
\text { 涨, 负值为跌, 零为持平。 }\end{array}$ & 负向 & $\%$ \\
\hline
\end{tabular}


雄安新区等 46 个城市和地区设立跨境电子商务综合 试验区的批复称, 要进一步完善跨境电子商务统计 体系, 实行对综合试验区内跨境电子商务零售出口 货物按规定免征增值税和消费税、企业所得税核定 征收等支持政策。实施扩大内需战略, 促进消费回 升。加快推进重大工程建设, 用好中央预算内投资 和地方政府专项债, 尽快形成实物工作量。工业和 信息化部批复组建国家高性能医疗器械创新中心和 国家集成电路特色工艺及封装测试创新中心。这些 利好消息使科创板的股价水涨船高, 各大机构给出 的预测净资产收益率平均值变高。截至5月6日收 盘, 科创板 100 只股票平均涨幅 $8.43 \%$, 共有 100 只股 票上涨。

由于在FSI的指标体系中，预测净资产收益率平 均值是权重最高的正向指标，而在1月17日和5月 6 日 这两日, 市场行情向好, 预测净资产收益率平均值 高, 所以FSI出现单日的大幅下降。这两个下降都属 于阶段性的下降调整。

综合来看, 本文构建的科创板市场系统性风险 指数较好的测度了科创板近期的系统性金融风险状 况。

\section{5. 结论}

通过验证, 本文构建的指标体系比较吻合科创 板市场的实际情况。理论上, 我们假定这六个指标 组合起来能够反映科创板市场的风险状态。通过实 证分析, 我们验证了这个指标体系能真实反映市场 风险状态, 从而验证了该指标体系构建的正确性。

本文构建的科创板市场系统性风险指数能较好 地测度科创板市场的系统性金融风险程度, 对政府 的监管有科学指导意义, 对投资人起到指示作用, 具有实用价值。

\section{致谢}

本文受到项目资金资助： 2020 年度中央财经大学大 学生创新创业项目 “构建中国的纳斯达克: 基于科 创板评估体系的研究（C2020103578）”、2020年 度国家民委民族研究项目 “后脱贫时代西部藏区乡 村振兴风险与内置金融研究（2020-GMB-030）”。

\section{参考文献}

[1] Illing M, Liu Y. Measuring financial stress in a developed country: An application to Canada [J]. Journal of Financial Stability, 2006, 2(3): 243265.

[2] FSB, IMF, BIS. World Economic Outlook[R], 2011.

[3] Hakkio C S, Keeton W R. Financial stress: What is it, how can it be measured, and why does it matter? [J]. Economic Review -Federal Reserve Bank of Kansas City, 2009, 94(2): 550.
[4]Balakrishnan R, Danninger S, Elekdag S, et al. The Transmission of Financial Stress from Advanced to Emerging Economies[J], Emerging Markets Finance and Trade, 2011(47):40.

[5]Gadanecz B, Jayaram K. Measures to Financial Stability a Review[R]. BIS,IFC Bulletin, 2010.

[6]Cardarelli R, Elekdag S, Lall S, Financial Stress and Economic Contractions[J].Journal of Financial Stability, 2011(7):78

[7]Louzis, Dimitrios P, Vouldis, Angelos T, \& Metaxas, Vasilios L. Macroeconomic and bank-specific determinants of non-performing loans in Greece: A comparative study of mortgage, business and consumer loan portfolios[J]. Journal of Banking and Finance, 2012,36(4):1012 1027.

[8]Bianco T, Gramlich D, et al. Financial stress index: A lens for supervising the financial system[M]. Cleverland: Federal Reserve Bank of Cleveland, Working Paper: 1237,2012 .

[9]Philip J Monin. The OFR Financial Stress Index[J]. Risks, 2017,7(1):1 21

[10]靳玉英.新兴市场国家金融风险传染性研究 [J].国 际金融研究.2013(05):4962.

[11]余文君.基于金融压力值数的上海 $\mathrm{A}$ 股市场系统 性金融风险研究[J].上海金融,2014(07):86 91.

[12]李敏波.基于股指波动率的股市压力指数构建 $[\mathrm{J}]$. 金融理论与实践,2013(05):31 34 .

[13]郑桂环.金融压力指数的构建及应用 $[\mathrm{J}]$.金融发展 评论, 2014(08):50 62 .

[14]许涤龙. 基于金融压力指数的系统性金融风险测 度研究 $[J]$.经济学动态,2015(04):69 78.

[15] 章曦. 中国系统性金融风险测度、识别和预测 $[\mathrm{J}]$. 中央财经大学学报,2016(02):45 52 .

[16]许悦.系统性压力综合指数的有效性研究 $[\mathrm{J}]$. 统计 与决策,2017(03):166 170.

[17]仲文娜.中国金融体系压力指数构建及有效性检 验[J].上海金融,2018(09):15 22.

[18]张同功.科创板运营风险评价与防范应对 [J].财会 月刊,2020(19):112 120 .

[19]陶秋月.我国科创板上市公司信用风险评估一一 基于 $\mathrm{KMV}$ 模型和有序 Logit 模型的研究 $[\mathrm{J}]$.上海立信 会计金融学院学报,2020(02):27 38 .

[20]申万宏源课题组. 科创板运行中相关风险点与防 范研究 $[J]$.证券市场导报,2020(01):2 10+20.

[21]曾长虹. 涨跌幅限制对流动性和波动性影响的因 子分析 $[J]$.金融研究,2004(04):37 44. 